\title{
Evaluation of the company's organizational culture
}

\author{
Olga Fokina ${ }^{1, *}$, Yuri Krupnov ${ }^{2,3}$ \\ ${ }^{1}$ Vyatka State University, 36, Moskovskaya str., 610000, Kirov, Russia \\ ${ }^{2}$ Moscow Region State University, 10A, Radio str., 105005, Moscow, Russia \\ ${ }^{3}$ Financial University under the Government of the Russian Federation, 49, Leningradsky prospect, \\ 125993, Moscow, Russia
}

\begin{abstract}
The article considers the possibility of applying Western methods of assessing organizational culture for the analysis of Russian companies. The question is raised about the different perception of organizational culture by management and performers. The authors show the need to simplify the methods for the initial assessment by the company's management. The article proposes questionnaires for assessing the elements of organizational culture in two formats, for managers and for performers. The methodology was tested on the example of a construction company, which has a wide gap in communications and geographical location between administrative employees and construction workers.
\end{abstract}

\section{Introduction}

Orientation of the company to strategic development inevitably leads it to the formation and development of organizational culture. Organizational culture encompasses values and behaviors that contribute to the unique social and psychological environment of a business. Organizational culture includes an organization's expectations, experiences, philosophy, and values that hold it together, and is expressed in its self-image, inner workings, interactions with the outside world, and future expectations. It is based on shared attitudes, beliefs, customs, and written and unwritten rules that have been developed over time and are considered valid [1].

Organizational culture is closely related to the cultural and historical features of the country [2]. Typically, the influence of national characteristics on the formation of the organizational culture is studied from the perspective of a sociocultural approach [3]. In this regard, standard techniques developed by American or European experts are not always suitable for the analysis of Russian experience [4].

The most popular methods for assessing and analyzing the development of organizational culture used in Russian companies are:

- OCAI (Organizational Culture Assessment Instrument) developed by Quinn and Cameron [5];

\footnotetext{
*Corresponding author: fokina_o_@mail.ru
} 
- DOCS (Denison Organizational Culture Survey) and DLDS (the Denison Leadership Development Surveys) developed by Daniel R. Denison [6];

- AGIL (Adaptation - Goal achievement - Integration - Legitimate) developed by $\mathrm{T}$. Parsons [7].

The most popular is the OCAI technique. The foundation is the idea of the four dominant types of corporate culture looming on the basis of the 'Competing Values Framework'. The disadvantage of this methodology is the inadmissibility of independent answers; accordingly, it is impossible to apply correlation analysis of data.

A study by A. Chanko showed that the averaged culture profiles of Russian companies do not have fundamental differences in general outline from foreign ones [8]. At the same time, a more detailed analysis of particular issues and averaged profiles of various hierarchical "horizons" revealed specifics that may indicate national characteristics of Russian management. In part, such features may appear due to the weak awareness by Russian leaders of their own values, as well as the need to coordinate them with other members of the management team. This means, the vision of organizational culture and its elements by employees of different hierarchy levels is different.

The aim of the study was to develop a methodology (diagnostic sheets) for assessing the organizational culture of the company by employees of various levels of the hierarchy. This helps to identify the "zone of discrepancies". Such areas indicate misconceptions and management weaknesses.

S. Mokeeva in her study of the perception of organizational culture by different types of employees showed the mutual influence of employees of one group (department) on the formation of opinion [9]. Thus, there is a grouping of perceptions that can distort the real picture. It is practically impossible to avoid such deviation, since even with the separation of employees during the survey, their opinion has commonality.

\section{Methods and Materials}

Diagnostic evaluation forms were structured into sections describing the relationships and behavior of company employees in various areas. The authors' goal was to form two questionnaire forms - for managers and performers - in order to reveal the consistency of understanding of all positions.

Methodologically, the development of questionnaires consisted of the following steps:

- setting the purpose of the survey;

- development of the survey structure (block diagram);

- development of principles for the formulation of questions;

- pilot testing of questionnaires;

- adjustment.

For the purpose of pilot testing, the organizational culture of the construction company VSS Ltd. was evaluated. The specifics of this company is a large gap between administrative and operational personnel. Workers are located in different geographical locations and rarely have direct communication. The main intermediary link is the project managers and construction managers. Most of the time they are located directly on construction sites, but at the same time they solve organizational issues with the administrative staff and company management. In total, the company employs 119 people, 67 of which are operational workers.

Testing was conducted in the format of an expert survey using the total sampling method. Thus, the results of the analysis are reliable, but they are applicable only for this company. 


\section{Results}

The questionnaires were structured as follows:

1. Corporate Culture. Corporate culture is rooted in an organization's goals, strategies, structure, and approaches to labor, customers, investors, and the greater community [10].

2. Communications. Organizational communication includes formal and informal communication throughout an organization, including communication among employees.

3. Organizational structure. An organizational structure is a system that outlines how certain activities are directed in order to achieve the goals of an organization. These activities can include rules, roles, and responsibilities. The organizational structure also determines how information flows between levels within the company.

4. Manager - employee communication. One of the most important ways of improving communication is making sure that lines of communication between managers and employees are open. Managers should be accessible.

5. Middle management level. Middle management is at the center of a hierarchical organization, subordinate to the senior management but above the lowest levels of operational staff. They provide guidance to lower-level managers and inspire them to perform better.

6. Motivation system. Motivation system consists of purposely chosen motivators which are all connected to each other; they satisfy the assumptions and the mission of company by encouraging the employees to certain behaviors and practices [11].

7. Staff. It refers to how employees feel about their culture and their jobs. The stronger a company's culture, the better employees understand what is expected of them and what they're working toward. Engaged employees are more likely to stay happy, motivated, and committed to your company.

The questionnaire for managers and administrative employees is listed in table 1.

Table 1. Questionnaire for Managers and Administrative employees.

\begin{tabular}{|l|}
\hline \multicolumn{1}{|c|}{ Corporate Culture } \\
\hline $\begin{array}{l}\text { 1. Has the company developed a corporate culture (a general view of business, the goals of the } \\
\text { enterprise, the same beliefs, cohesion, a high level of trust, ethics and rules of conduct, corporate } \\
\text { style)? }\end{array}$ \\
\hline 2. Does the company have a positive image as an employer? \\
\hline 3. Does the company have strict discipline, rules of conduct and interaction? \\
\hline 4. Are general positive traditions formed in the enterprise? \\
\hline \multicolumn{1}{c|}{ Communications } \\
\hline 1. Are the ways of transmitting information at the enterprise clear and simple? \\
\hline 2. Are remote communication channels (email, website, social networks, etc.) actively used? \\
\hline $\begin{array}{l}\text { 3. Are printed communication channels (information stands, regular corporate publications, } \\
\text { brochures, etc.) actively used? }\end{array}$ \\
\hline 4. Are meetings and conferences effective? \\
\hline $\begin{array}{l}\text { 5. Is the feedback system working effectively (the ability of employees to signal problems, make } \\
\text { proposals)? }\end{array}$ \\
\hline 6. Is the staff well, fully and on time informed of changes? \\
\hline 7. Are communication channels with employees convenient? \\
\hline \\
\hline 1. Is the organizational structure clear and understandable to all employees? \\
\hline 2. Does the company clearly define the job responsibilities of each employee? \\
\hline 3. When a new task appears, is it always immediately clear who should deal with it? \\
\hline 4. Is it clear who to contact on what issues? \\
\hline
\end{tabular}




\section{Manager - employee communication}

1. Are direct managers always available to subordinates?

2. Does the company have a convenient and effective way to convey problems to senior management?

3. Are the managers experts, assistants, and authority for subordinates?

\section{Middle management level}

1. Is the opinion of site managers and foremen considered when appointing Project Managers?

2. Do the mid-level managers (project managers, site managers, superintendents) have high competence, are perfectly able to plan, set tasks, control, motivate and ask workers for their opinions?

3. Are mid-level managers (project managers, site managers, superintendents) ready for change and loyal to the company?

4. Do the mid-level managers (project managers, site managers, foremen) constantly initiate improvements?

Motivation system

1. Does each employee clearly understand the prospects of their career growth?

2. Does the enterprise have a personnel reserve for managerial positions?

3. Is there an opportunity to improve qualifications at the company?

4. Does the company provide information on available ways of continuing education in third-party organizations?

5. Does the company hold internal corporate contests and competitions?

6 . Does the company provide benefits and organize leisure activities?

7. Do employees have a comfortable and safe workplace?

8. In addition to cash bonuses, does the company practice presenting letters, awards, intangible incentives?

9. Does the company have a clearly built system of material rewards for success in work?

10. Does the enterprise have a clearly structured system of penalties (fines) for misconduct and inefficient work?

1. The ratio of the number of managers and the number of workers is optimal?

2. Does the company have no or low staff turnover?

3. Are job vacancies easy to find and easy to find?

4. Are the problems and complaints of employees regarding labor issues (to the personnel department) easily and quickly resolved?

The proposed questionnaire suggests 3 possible answers: yes, no, or partially. It is necessary to comment on the reasons when answering "partially". This will help to detail the problem and more accurately approach its solution.

The questionnaire for workers has differences. In the 'Manager - employee communication' section, senior management and direct management are separated, respectively, there are two questions about the availability of top-managers and direct manager. Another difference is the replacement of the 'Middle management level' block with a 'Low management level (foremen)'. The questions have no differences, but they are aimed at the direct managers with whom the workers have daily work.

\section{Discussion}

Surveys are usually delegated to the human resources department. A typical mistake in interviewing employees is to delegate it to the supervisor. Psychological pressure factors can cause biased totals. Ideally, it is necessary to organize an anonymous survey and try to ensure the absence of reprisals against subordinates by direct managers in case of unsatisfactory assessments.

An evaluation of the organizational structure in the pilot company confirmed a large gap between administrative and operational staff. This gap was visible even in the responses of 
middle and lower managers. It suddenly turned out that foremen and project managers lacked equipped workplaces in the office. Despite the fact that they spend most of their working time at construction sites, coming to the office, they also need a workplace. As a result, a working office area was equipped in the administrative building of the company for middle and lower level managers. There are no fixed workplaces in the working zone, but 3 universal office workplaces with office equipment and a meeting room are equipped. Further, the management set a goal to evaluate the effectiveness of the implementation of this tool and analyze the working hours of those employees in the office.

Another problem of the organizational structure block was the lack of understanding of employees who is responsible for what. Also, when new problems arise in the company, it is not always clear who should deal with them. In general, the understanding of organizational structure by employees is at a very low level. In order to clarify the job responsibilities and a clear separation of functions and tasks, it was decided to apply an interesting solution: the employees were asked to independently describe their responsibilities and tasks, their functionality. Next, responsibility matrices will be formed for a clear delineation of powers.

Important in solving this problem is timely feedback. In the company as a whole, a lot of information is filtered at the middle level. Mid-level managers, in an attempt to protect top management from unnecessary problems, as well as showing independence, often retain vertical flow information, both from top management to employees and in the opposite direction.

An obvious advantage of the company, which was highlighted by almost all employees, was an established electronic communication system. The company has organized corporate mobile communications (free of charge for employees), VOIP communication channels such as Skype, Viber, WhatsApp are actively used. Employees form groups for communication, and the company maintains its own news and information channels. Additionally, the positive impact of the company's developing ERP system was noted.

However, the communications unit showed a lack of visualized information, such as information stands. The transparency of the information that modern companies strive for implies its accessibility. An operational management system is based on visualization. This is especially true for construction sites working in compressed deadlines. Identification of this problem launched a whole project to improve operational management. The company overestimated its performance indicators, linking them with the requirements of service customers, and also developed a system for visualizing these indicators. Further, visualization boards were placed in public places on construction sites.

In general, assessing the level of development of the organizational structure gives a much wider understanding of the state of the company than just culture. In the process of analysis, non-obvious problems are revealed, and the employee's voice comes to the fore. Employees are involved in the process of continuous improvement, becoming more active and loyal to the company. Based on this initial analysis, you can start the process of continuous improvement in the company.

\section{Conclusion}

Today, large Russian companies form a pro-western organizational culture, therefore, foreign methods of its assessment are quite easily suitable for its diagnosis. Of particular interest are small and medium-sized companies, which are in their heyday and are trying to build their business correctly. Such companies often lack experience and relevant knowledge. In the conditions of fierce competition, companies minimize the costs of supporting processes, that is, they do not contain specialists in organizational culture. 
Managers try to make out on their own in the interweaving of elements of organizational culture, but subjectivity and the specificity of qualifications do not always allow this.

The developed questionnaires are the simplest tool for the initial understanding of the areas to which manager need to pay attention and diagnose deviations in the behavior of personnel. Also, the results of the polls will help to see disagreements in the perception of certain elements of the organizational culture by administrative and operational workers. All this helps to quickly adjust the work and build a proactive model of company management.

\section{References}

1. Organizational Culture, Business Dictionary http://www.businessdictionary.com/definition/organizational-culture.html

2. D. Ralston, D. Holt, Y. Kai-Cheng, Journal of International Business Studies 28(1), 177 (1997)

3. T. To, Y. Arutyunov, Naukovedenie 1(9) (2017)

4. C. Fey, D. Denison, Organization Science 14(6), 686 (2003)

5. K. Cameron, R. Quinn, Diagnosing and changing organizational culture (AddisonWesley, 1999)

6. D. Denison, Corporate Culture and Organizational Effectiveness (John Wiley, 1990)

7. T. Parsons, The Social System (London, Routledge \& Kegan Paul Ltd, 1970)

8. A. Chanko, Russian Management Journal 4, 29 (2005)

9. A. Mottaeva, E3S Web of Conferences 110, 02164 (2019) doi.org/10.1051/e3sconf /201911002164

10. S. Mokeeva, Acmeolog 4(56), 341 (2015)

11. V. Holodkova, A. Mottaeva, T. Pokrovskaya, E3S Web of Conferences 164, 11043 (2020) https://doi.org/10.1051/e3sconf /202016411043

12. E. Ganebnykh, O. Lezhnina, T. Zhilkina, E3S Web of Conferences 164, 10033 (2020) 